\title{
Computer Vision Syndrome: Prevalence And Predictors Among College Staff And Students
}

\author{
${ }^{1}$ Nikunj Gupta, ${ }^{2}$ Tania Moudgil, ${ }^{3} *$ Bhuwan Sharma \\ ${ }^{1}$ MBBS Student, ${ }^{2}$ Associate Professor,Department Of Ophthalmology ${ }^{3}$ Assistant Professor, Department Of \\ Community Medicine, PIMS, Medical College, Jalandhar, Punjab
}

\begin{abstract}
:
Introduction: Computer Vision Syndrome (CVS) is a relatively new entity described as a symptomatic complex of various eye and vision related problems, resulting from prolonged computer use. It is caused by multiple factors which include ergonomic factors, individual responses and time spent by individual on computer.

Objectives: 1) To study prevalence of Computer Vision Syndrome in college staff and students in Punjab Institute of Medical Sciences, Jalandhar. 2) To evaluate the factors attributing to Computer Vision Syndrome. Materials \& Methods: The study was an interview based, cross sectional study. A pre-formed, semi-structured questionnaire was used for collection of information regarding socio-demographic data; ophthalmic and clinical examination. Detailed information was collected regarding duration, frequency and timing of computer use and various asthenopic symptoms. Data was analyzed by SPSS 21.0 (SPSS Inc., Chicago, IL, USA) using appropriate statistical tests to find the association of CVS with variables of computer usage.

Results: A total of 456 subjects aged 18-67 years were studied with mean age 21.5 years. Number of computer users were 424 (93\%) and non-users were 32 (7\%).About 66.3\% subjects using were suffering from aesthenopic symptoms during or after work on computer. A significant association was observed between asthenopic symptoms and duration and years of computer usage. About $42.5 \%$ of subjects are not taking any medical help or other intervention for the symptoms.

Conclusion: General prevalence of CVS is high in the study population. The factors associated with the severity of CVS were the duration of usage and hours of usage per day. About half of the people don't seek medical help for it.
\end{abstract}

Keywords: Computer Vision Syndrome, Asthenopic Symptoms, Medical Students

\section{Introduction}

In the present era, use of computers has increased manifolds and its use has been associated with increased health risks, especially for eyes. Computer Vision Syndrome (CVS) is one such problem, affecting more and more people as these peopleare constantly in front of computer screens. CVS describes a symptom complex of various eye and vision related problems that result from prolonged computer use.

According to National Institute of Occupational Safety and Health, CVS affects about $90 \%$ of people, who spends 3 hours or more a day at a computer [1]. Another study in Malaysia was conducted on 795 college students aged 18-25 years. They experienced headaches along with eyestrain, with $89.9 \%$ of the students surveyed feeling any type of symptoms of CVS [2].

Computer has become a necessary evil. Working at it is not free from health hazards and it leads to repetitive stress disorder characterized by symptom complex of eye strain, tired eyes, irritation, burning sensation, redness, dry eyes, blurred and double vision, refractive errors, apart from non-ocular complaints like neck, shoulder \& back pain collectively termed as CVS [3]. It is caused by multiple factors which include ergonomic factors [4], individual responses and time spent by individual on computer. The treatment needs to be tailored to the individual patient. The problem of CVS is very new to medical sciences and is under investigation to explain the mechanism of disease and to find a solution.

Hence this institution based study was undertaken to find the prevalence and various factors associated with the Computer vision syndrome.

\section{Material \& Methods}

The study was an interview based, cross sectional study. Participants were selected from PIMS college staff and students. Informed consent was taken from all the participants and confidentiality was reassured. A pre-formed, semi-structured questionnaire was used for collection of information regarding socio-demographic data; ophthalmic and clinical examination. Detailed information was collected regarding duration, frequency and timing of computer use. Asthenopic symptoms taken into consideration were: 
1. Visual(Blurred vision, Slow refocusing, Doubling of vision, Squinting, Changes in colour perception, visual aquity)

2. Ocular (Irritated or sore eyes, Itching and burning eyes, Excessive tearing, Dry eyes, Sore or hurting eyes)

3. General (Eyestrain, Headache, Eye fatigue, Tired eyes)

4. Light (Flickering sensations, Glare, Light sensitivity, Photophobia)

5. Muscle (Neck or shoulder tension or pain, Back pain, Pain in arms, hands, wrists or shoulders; Hip, leg, ankle or foot)

6. Other (Tension, Excessive physical fatigue, Irritability, Increased nervousness, more frequent errors, General fatigue or drowsiness.)

Data was analyzed using SPSS software ver. 21.0 (SPSS Inc., Chicago, IL, USA). Subjects were divided into computer users and non-users and users were divided on the basis of presence or absence of CVS symptoms. Appropriate statistical testswere usedbased on type and distribution of datato find the various association of CVS. A p- value of $<0.05$ was taken as level of significance.

\section{Results}

A total of 456 subjects aged 18-67 years were studied with mean age 21.5 years. Out of the total 456 subjects, $46.5 \%$ were males and $53.5 \%$ were females. Number of computer users were (93\%) and non-users were 32 (7(table 1). About $66.3 \%$ subjects were suffering from aesthenopic symptoms during or after work on computer. Out of $93 \%$ subjects using computer, $25.4 \%$ individuals told they had persistence of asthenopic symptoms while not working on computer. Maximum number of subjects were using computer for less than 3 hours/day (63.2\%) followed by 3-6 hours/ day (23.8\%) while 4\% were using for more than 9 hours a day (Table 2). About one third of subjects were using computer since 9 to 12 years $(63.2 \%)$ while $29.7 \%$ were using computers since 5 to 8 years (Table 4). A significant association was observed between asthenopic symptoms and duration and years of computer usage (Table 3 and 5). About $42.5 \%$ of subjects are not taking any medical help or other intervention for the symptoms. A total of $13.2 \%$ subjects preferred washing of eyes with cold water, $5.3 \%$ of subjects used medicated eye drops daily after detection of the symptoms, $30.3 \%$ subjects opted for withdrawal or sleeping to reduce the symptoms, $7.9 \%$ subjects chose using spectacles for reduction of symptoms, $7.9 \%$ subjects had to switch off ceiling fans or AC for reduction of symptoms and $6.1 \%$ of subjects chose other indigenous methods for reduction of symptoms like almond and milk combination,using screen dimmer application on computers,proper lighting of room, keeping computer at distance and yoga.

\section{Discussion}

In present study, $66.3 \%$ subjects were suffering from aesthenopic symptoms during or after work on computer.In a comprehensive national survey on the prevalence of CVS in computer office workers from a South Asian country by Ranasinghe et al., the 1 year prevalence of CVS was $67.4 \%$ [5]. Previous studies on CVS from Malaysia $(68.1 \%)$ and Nigeria $(74.0 \%)$ have demonstrated similar results [6,7]. In another study among medical and engineering students in Chennai has found a higher prevalence of CVS (80.3\%) [8], whereas a study among keyboard users in Mauritius has found a lower prevalence of CVS (59.9\%) [9]. The higher prevalence observed in the study from Chennai $(80.3 \%)$ is possibly due to the involvement of neck and shoulder pain as a symptom of CVS by the study team, whereas our definition of CVS consisted only of eye/visual symptoms apart from headache. Also in our study only the symptoms which lasted at least 1 week were considered as symptoms of CVS whereas they had no specification on duration of symptoms and therefore included even transient symptoms [8].

Increased frequency of computer usage and duration of usage were significantly associated with risk of CVS. Evidence from many other studies supports these findings [6,10,11]. Rahman and Sanip, in their study reported that spending more than $7 \mathrm{~h}$ per day on computer at work was a significant predictor for CVS (OR: 2.01) [7]. Mutti and Zandic reported more pronounced visual symptoms in people spending 6-9 h daily at a computer [12], while Stella et al. observed the same in people using computer more than 8 h daily [13].

There are several limitations to our study; the cross sectional design limits the inference of causality and can only demonstrates an association between CVS and identified risk factors. Hence, prospective follow up studies among computer office workers without CVS is required to identify risk factors for CVS during subsequent follow up. Not including neck and shoulder pain as a symptom of CVS was also a limitation. It has been considered as an extra-ocular symptom of CVS in many studies and reviews on CVS [8,10,14-16].

\section{Conclusion}

General prevalence of CVS is high in the study population. The factors associated with the severity of CVS were the duration of usage and hours of usage per day. About half of the people don't seek medical help 
for it. However, further prospective follow up studies are required to establish causality for identified risk factors.

\section{Acknowledgement}

Authors acknowledge the immense help received from the scholars whose articles are cited and included in references of this manuscript. The authors are also grateful to authors/ editors/ publishers of all those articles, journals and books from where the literature for this article has been reviewed and discussed.

\section{Conflict Of Interest}

None declared

\section{References}

[1]. Travers PH. Stanton BA. Office workers \& video display terminals: physical, psychological \& ergonomic factors. AAOHN j. 2002;50: 489-93

[2]. Himebaugh NL, Begley CG, Bradley A, Wilkinson JA. Blinking and tear break-up during four visual tasks. Optometry \& Vision Science. 2009 Feb 1;86(2):E106-14.

[3]. Becoming a squinter nation (internet). Wall street journal. August 17, 2010. Avaliable at: http://www.wsj.com/articles/SB10001424052748704868604575433361436276340

[4]. Readdy SC, Low CK et al. Computer vision syndrome:a study of knowledge and practises n university students. Nepal J Opthalmol. 2013;5(10):161-168.

[5]. Ranasinghe P, Wathurapatha WS, Perera YS, Lamabadusuriya DA, Kulatunga S, Jayawardana N, Katulanda P. Computer vision syndrome among computer office workers in a developing country: an evaluation of prevalence and risk factors. BMC research notes. 2016 Mar 9;9(1):1.

[6]. Akinbinu TR, Mashalla Y. Knowledge of computer vision syndrome among computer users in the workplace in Abuja, Nigeria. Pretoria: University of South Africa; 2012.

[7]. Rahman ZA, Sanip S. Computer user: demographic and computer related factors that predispose user to get computer vision syndrome. Int J Bus, Humanit Technol. 2011;1(2):84-91.

[8]. Logaraj M, Madhupriya V, Hegde S. Computer vision syndrome and associated factors among medical and engineering students in chennai. Ann Med Health Sci Res. 2014;4(2):179-185.

[9]. Subratty A, Korumtollee F. Occupational overuse syndrome among keyboard users in Mauritius. Indian J Occup Environ Med.2005;9(2):71. doi: 10.4103/0019-5278.16745.

[10]. Reddy SC, Low C, Lim Y, Low L, Mardina F, Nursaleha M. Computer vision syndrome: a study of knowledge and practices in university students. Nepal J Ophthalmol. 2013;5(2):161-168.

[11]. Portello JK, Rosenfield M, Bababekova Y, Estrada JM, Leon A. Computer-related visual symptoms in office workers. Ophthalmic Physiol Opt. 2012;32(5):375-382. doi: 10.1111/j.1475-1313.2012.00925.x. [PubMed] [Cross Ref]

[12]. Mutti DO, Zadnik K. Is computer use a risk factor for myopia? J Am Optom Assoc. 1996;67(9):521-530. [PubMed]

[13]. Chiemeke SC, Akhahowa AE, Ajayi OB. Proceedings of the World Congress on Engineering. London: International Association of Engineers; 2007. Evaluation of vision-related problems amongst computer users: a case study of University of Benin, Nigeria.

[14]. Shrestha GS, Mohamed FN, Shah DN. Visual problems among video display terminal (VDT) users in Nepal. J Optom.2011;4(2):56-62. doi: 10.1016/S1888-4296(11)70042-5.

[15]. Yan Z, Hu L, Chen H, Lu F. Computer vision syndrome: a widely spreading but largely unknown epidemic among computer users. Comput Hum Behav. 2008;24(5):2026-2042.

[16]. Loh K, Redd S. Understanding and preventing computer vision syndrome. Malays Fam Phys. 2008;3(3):128-130.

Tables

Table 1: Distribution of subjects based on Computer usage

\begin{tabular}{|l|c|c|}
\hline Computer Users & N & \% \\
\hline Yes & 424 & $93.0 \%$ \\
\hline No & 32 & $7.0 \%$ \\
\hline Total & 456 & $100.0 \%$ \\
\hline
\end{tabular}

Table 2: Distribution of subjects based on Duration of Computer usage

\begin{tabular}{|l|c|c|}
\hline Duration of Computer Use & $\mathbf{N}$ & $\mathbf{\%}$ \\
\hline$<3$ hours & 268 & $63.2 \%$ \\
\hline $3-6$ hours & 101 & $23.8 \%$ \\
\hline $6-9$ hours & 38 & $9.0 \%$ \\
\hline$>9$ & 17 & $4.0 \%$ \\
\hline Total & 424 & $100.0 \%$ \\
\hline
\end{tabular}

Table 3: Association of Asthenopic symptoms with Duration of Computer usage

\begin{tabular}{|l|c|c|c|c|c|c|c|}
\hline $\begin{array}{l}\text { Duration of Computer } \\
\text { Use }\end{array}$ & $\mathbf{N}$ & Visual & Ocular & General & Light & Muscle & Other \\
\hline$<3$ hours & 268 & $42.8 \%$ & $56.9 \%$ & $60.5 \%$ & $25.4 \%$ & $64.4 \%$ & $63.5 \%$ \\
\hline $3-6$ hours & 101 & $44.0 \%$ & $61.2 \%$ & $68.0 \%$ & $32.0 \%$ & $74.0 \%$ & $74.0 \%$ \\
\hline $6-9$ hours & 38 & $72.0 \%$ & $66.7 \%$ & $75.0 \%$ & $38.9 \%$ & $83.3 \%$ & $83.3 \%$ \\
\hline$>9$ & 17 & $81.3 \%$ & $76.7 \%$ & $83.3 \%$ & $43.3 \%$ & $88.9 \%$ & $83.3 \%$ \\
\hline p- value & & $<\mathbf{0 . 0 5}$ & $<\mathbf{0 . 0 5}$ & $<\mathbf{0 . 0 5}$ & $<\mathbf{0 . 0 5}$ & $<\mathbf{0 . 0 5}$ & $<\mathbf{0 . 0 5}$ \\
\hline
\end{tabular}


Table 4: Distribution of subjects based on years of Computer usage

\begin{tabular}{|l|c|c|}
\hline Years of Computer Usage & $\mathbf{N}$ & \% \\
\hline$</=4$ & 85 & $20.0 \%$ \\
\hline 5 to 8 & 126 & $29.7 \%$ \\
\hline 9 to 12 & 146 & $34.4 \%$ \\
\hline$>12$ & 67 & $15.8 \%$ \\
\hline Total & 424 & $100.0 \%$ \\
\hline
\end{tabular}

Table 5: Association of Asthenopic symptoms with years of Computer usage

\begin{tabular}{|l|c|c|c|c|c|c|c|}
\hline $\begin{array}{l}\text { Years of Computer } \\
\text { Usage }\end{array}$ & N & Visual & Ocular & General & Light & Muscle & Other \\
\hline$</=4$ & 85 & $45.2 \%$ & $56.1 \%$ & $78.6 \%$ & $35.7 \%$ & $60.0 \%$ & $70.0 \%$ \\
\hline 5 to 8 & 126 & $49.2 \%$ & $63.1 \%$ & $85.9 \%$ & $23.4 \%$ & $76.2 \%$ & $73.4 \%$ \\
\hline 9 to 12 & 146 & $41.9 \%$ & $63.4 \%$ & $88.9 \%$ & $32.7 \%$ & $81.3 \%$ & $76.7 \%$ \\
\hline$>12$ & 67 & $45.5 \%$ & $70.6 \%$ & $91.8 \%$ & $39.4 \%$ & $81.8 \%$ & $81.2 \%$ \\
\hline p- value & & $\mathbf{0 . 7 8}$ & $<\mathbf{0 . 0 5}$ & $<\mathbf{0 . 0 5}$ & $<\mathbf{0 . 0 5}$ & $<\mathbf{0 . 0 5}$ & $<\mathbf{0 . 0 5}$ \\
\hline
\end{tabular}

